\title{
Morphological analysis of three populations of Anopheles (Nyssorhynchus) nuneztovari Gabaldón (Diptera: Culicidae) from Colombia
}

\author{
Mayury Fajardo Ramos, Ranulfo González Obando/ ${ }^{+}$, Marco Fidel Suárez, David López, \\ Richard Wilkerson", Maria Anice Mureb Sallum² \\ Facultad de Ciencias Naturales y Exactas y Facultad de Salud, AA 25623, Universidad del Valle, Cali, Colombia 'Division of Entomology, \\ Walter Reed Army Institute of Research, Silver Spring, MD, US ${ }^{2}$ Departamento de Epidemiologia, Faculdade de Saúde Pública, \\ Universidade de São Paulo, SP, Brasil
}

Based on the results of comparative analyses of 1,039 specimens of several progenies of Anopheles nuneztovari from three localities in Colombia, eight costal wing spot patterns were observed. Patterns I and III were the most frequent: $77.96 \%$ and $11.36 \%$, respectively. Using the diagnostic characters ratio of the length of the basal dark area of hind tarsomere II/length of hind tarsomere II, ratio of the length of the humeral pale spot/length of the pre-humeral dark spot, and the ratio of the length of the subcostal pale spot/length of the distal sector dark spot (DS-III/Ta-III, $H P / P H D, S C P / D S D)$ approximately $5 \%$ of the adult females were misidentified as a species of Nyssorhynchus, different from An. nuneztovari. Approximately 5\% of the specimens showed DS-III/Ta-III, ratio less than 0.25 (range $0.21-0.24$ ), and among them $3.34 \%$ shared a HP/PHD ratio less than 1.50 . Consequently, $1.52 \%$ of An. nuneztovari individuals can be misidentified as Anopheles oswaldoi. In those specimens with the DS-III/Ta-III, ratios higher than $0.25,34.45 \%$ displayed $S C P / D S D$ values greater than 0.50 and of these, $3.65 \%$ displayed HP/PHD values greater than 1.8. This combination of characters could lead one to misidentify samples of An. nuneztovari as Anopheles rangeli. Similarly, 2.43\% of the females could be identified erroneously as either Anopheles aquasalis or Anopheles benarrochi. Individuals with a HP/PHD ratio greater than 2.0, could be misidentified as Anopheles trinkae, Anopheles strodei or Anopheles evansae. A distinct combination of diagnostic characters for An. nuneztovari from Colombia is proposed.

Key words: intraspecific variation - Anopheles nuneztovari - malaria vectors - taxonomy - Colombia

Because of inter- and intraspecific phenotypic variation, the various morphological studies on the species belonging to Anopheles subgenus Nyssorhynchus have focused on establishing principal diagnostic differences of each species for an accurate, and easy, identification. However, this strategy does not address overall species variability for mosquito specialists. When users recognize variation not reflected in the keys it can lead to speculation, often correct, that there are many Neotropical Anopheles species that are complexes of sibling species (Rosas-Freitas et al. 1998), at times difficult to morphologically differentiate in some or all developmental stages. This is the situation with Anopheles (Nyssorhynchus) nuneztovari, which has been suspected for some decades as constituting a complex of at least three distinct polytene chromosomal forms. Initially, ecological and ethological observations of distinct populations of this species suggested that it consisted of two different allopatric forms (Elliott 1972), one from Brazil, Surinam, and Ecuador and the other from Western Venezuela and Northern Colombia. Later it was postulated that they

Financial support: National Program of Science and Technology of Colciencias (Code No. 1106-04-168-95), Universidad del Valle, Cali, Colombia

+Corresponding author: ranulfo@univalle.edu.co

Received 28 September 2007

Accepted 14 February 2008 constituted two chromosomal allopatric races (Kitzmiller et al. 1973). Along the same lines, Conn et al. (1993) presented evidence of a distinct cytotype of An. nuneztovari, informally designated cytotype $\mathrm{C}$, which was present in Western Colombia and Venezuela and in the Northwest of the Andean Cordillera. Conn et al. (1998), on analyzing the lineage of isozymes and 46 mtDNA restriction fragment length polymorfism haplotypes, found five lineages among the examined populations that possibly represented incipient species (Lounibos \& Conn 2000). In Colombia, various studies have confirmed the presence of only one of the cytotypes possibly belonging to cytotype C (Scarpassa et al. 1999, Posso et al. 2003), which is possibly similar to that also found in Northeastern Venezuela.

From a morphological perspective, various studies have demonstrated that this species exhibits great variation in costal dark and pale spots, wing patterns, ratio of the length of the dark basal area of the hind tarsomere II (DS-Ta-III ${ }_{2}$ )/length of hind tarsomere II (Ta-III ${ }_{2}$ ), and male genitalia (Sutil 1976, Faran 1980, Delgado \& RubioPalis 1992, Hribar 1994, 1995). Hribar (1994) analyzed the male genitalia of specimens from the three cytotypes mentioned above he found that, even though there was morphometric variation in some of the characters related to collection site, they seemed to be of limited utility for delimiting possible relationships among cytotypes. More recently Bergo et al. (2007) did morphological comparisons of the aedeagus of two species from the state of 
Amapá (Brazil), clearly differentiating Anophelis goeldii Rozeboom and Gabaldon, from An. nuneztovari, the former considered by Lane (1953) to be a synonym of $A n$. nuneztovari. This led the authors to propose complementary molecular studies to clarify this. The variation observed in the wings of subgenus Nyssorhynchus not only includes the size of the different costal spots (Wilkerson $\&$ Peyton 1990), but also the number of patterns that can be observed (Delgado \& Rubio-Palis 1993, Hribar 1995, Rubio-Palis 2000, González 2001). Three characters often used in the differentiation of species of the Oswaldoi Group are the ratio of the length of the basal dark area of hind tarsomere II/length of hind tarsomere II (DS-Ta$\mathrm{III}_{2} / \mathrm{Ta}-\mathrm{III}_{2}$ ), ratio of the length of the humeral pale spot/ length of the pre-humeral dark spot (HP/PHD), and the ratio of the length of the subcostal pale spot/length of the distal sector dark spot (SCP/DSD).

We found that because of interspecific morphological variation that there was overlap of measurements and ratios used in Faran's (1980) and Faran and Linthicum's (1981) identification keys. We even found that it was not possible to reach an accurate species identification for several individuals obtained from their respective progeny broods (females) of species of the Oswaldoi Group. As a consequence, a high percentage of individuals of the same species may be misidentified as two or three distinct taxa. In this study, we analyzed morphological character variation in siblings from families of An. nuneztovari collected in three distant localities in Colombia. Additionally, we examined distinct pale and dark spot wing patterns on the basis of variation observed in three wing spot ratios that were previously evaluated for species of the Oswaldoi Group (Delgado \& Rubio-Palis 1993), and suggest possible solutions for species distinction using morphology.

\section{MATERIALS AND METHODS}

Study area - Samples of An. nuneztovari were collected from three municipalities in widely separated departments of Colombia (Valle del Cauca, Cordoba, and Norte de Santander) (Fig. 1): Buenaventura (3 53' $36^{\prime \prime} \mathrm{N}$ $\left.77^{\circ} 04^{\prime} 11^{\prime \prime} \mathrm{W}\right), 7 \mathrm{~m}$ above sea level, $27^{\circ} \mathrm{C}$ annual average temperature; Tierralta $\left(8^{\circ} 10^{\prime} 25^{\prime \prime} \mathrm{N} 76^{\circ} 03^{\prime} 33^{\prime}\right.$ 'W), $98 \mathrm{~m}$ above sea level, $28^{\circ} \mathrm{C}$ annual average temperature; and, Tibu ( $8^{\circ} 38^{\prime} 53^{\prime}$ 'N $\left.72^{\circ} 44^{\prime} 22^{\prime \prime} \mathrm{W}\right), 115 \mathrm{~m}$ above sea level, $28^{\circ} \mathrm{C}$ annual average temperature (Instituto Geográfico “Agustín Codazzi” 1980).

Progeny broods - Individual female mosquitoes were collected from 18:00 to 22:00 from human bait. No more than 25 field-collected adult females were kept alive inside plastic vials, and transported in coolers to the insectory situated in the Sección de Entomología of the Universidad Del Valle. Females were fed on guinea pig blood and a $10 \%$ sucrose solution to develop ovaries and lay eggs. After $24 \mathrm{~h}$, those females in good condition and well-fed were separated for oviposition into individual 100 cc plastic vials, with $100 \%$ cotton fiber bottoms, covered with filter paper (oviposition vials). These females were maintained in thermic boxes to maintain mean temperatures around $26^{\circ} \mathrm{C}$ with high humidity (not measured). Daily observation was carried out to identify recent oviposition.

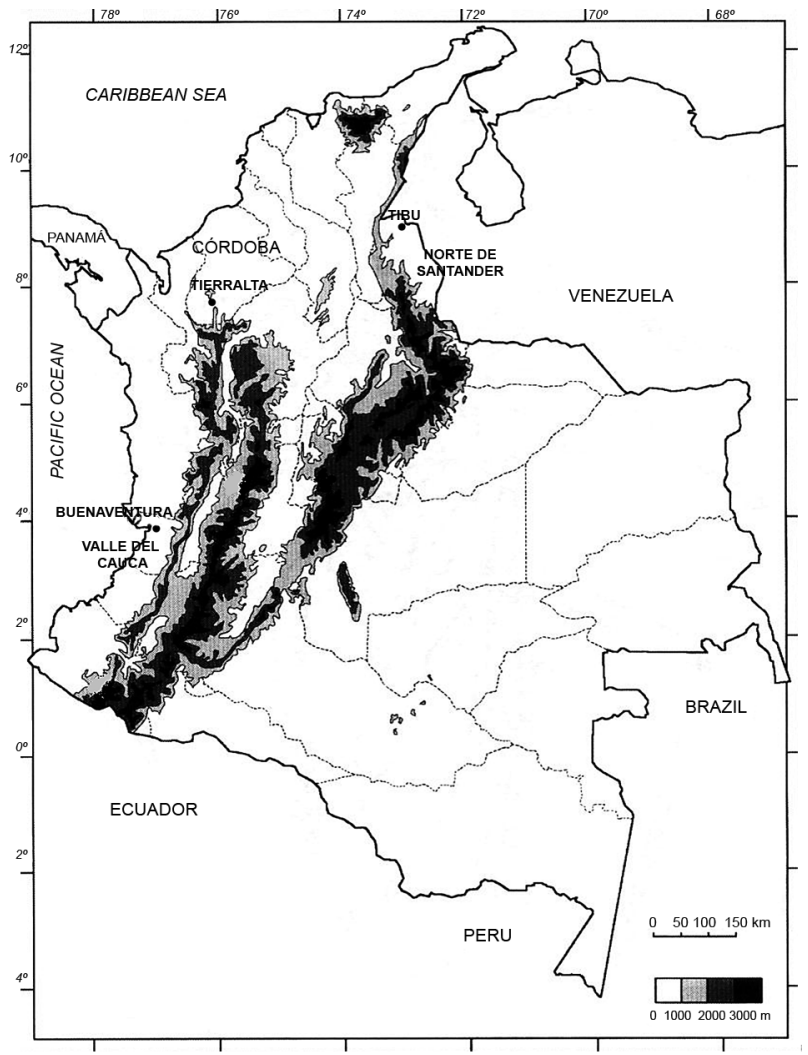

Fig. 1: map showing the geographical position of the sampled localities from which we obtained isogenic progenies of Anopheles nuneztovari in Colombia.

After oviposition, each adult female was removed from the vial and killed in a refrigerator at $-4^{\circ} \mathrm{C}$, and pinned, with each individual labeled to maintain the association between each female and the corresponding egg batch. Eggs from each female were kept separate and raised to adults. Larvae were raised in distilled water and fed with a mixture of yeast and pulverized rabbit food. Fourth instar larvae were separated into small plastic vials to obtain adult males and females with associated larval and pupal exuviae, which were then preserved in $80 \%$ ethanol. Adults were fed with a $10 \%$ solution of sucrose before being killed at $-4^{\circ} \mathrm{C}$. Each specimen was labeled with the same accession code of its respective mother in addition to its individual number. Samples employed in the analyses were identified on the basis of the external anatomical features of the male genitalia, in accordance with Faran and Linthicum's (1981) description and species identification key.

Morphological analysis - Each individual was examined and those morphological characters that are normally employed for species identification were measured. Characters were selected following Faran (1980) and RubioPalis (2000). Because pale and dark wing spots exhibit important species diagnostic characters, they were fully measured and analyzed (Fig. 2A) (Wilkerson \& Peyton 1990), as was hindtarsomere II (Fig. 2B). Measurements were made with a Nikon stereomicroscope. Total wing length was measured in addition to presence or absence 
of wing spots and their respective lengths on the costal vein as follows (BP+PHP, PHD, HP, HD, PSP, PSD, SP, PRSD, ASP, DSD, SCP, PD, PP, AD). Both the length of hindtarsomere II and the ratio of the length of dark basal area of the hindtarsomere II/length of the hindtarsomere II were measured (Fig. 2B). The following are analyses of adult male and female dark and pale costal wing spots, variation of the HP/PHD and SCP/DSD, and ratio of the length of basal dark spot of hindtarsomere II (DS-Ta$\left.\mathrm{III}_{2}\right) /$ length of hindtarsomere II (Ta-III ${ }_{2}$ ) of three populations of An. nuneztovari.
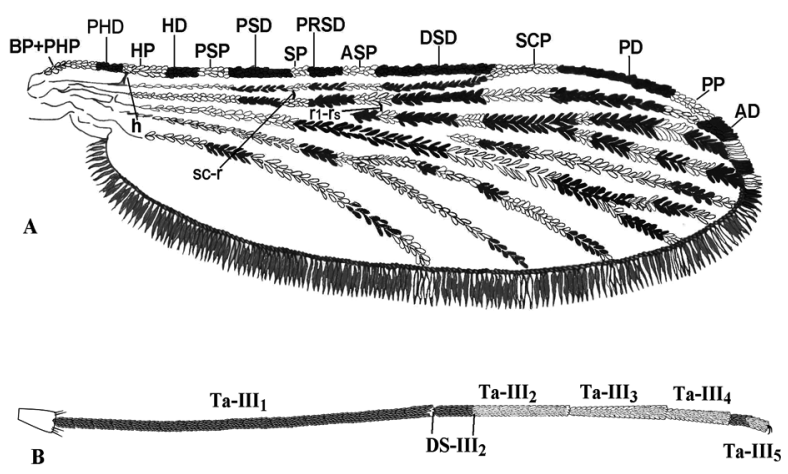

Fig. 2: Anopheles nuneztovari. A: pattern of dark and pale spots of the wing, showing pattern designated I (all spots separate); B: hind tarsomeres. DS = Dark spot (from González \& Carrejo 2007).

\section{RESULTS AND DISCUSSION}

Variation of the costal vein spots of males and females - Male and female adults from 74 families of An. nuneztovari were analyzed, totaling 1,039 specimens: male $(n=636)$ and female $(n=403)$, with 450 from Tierralta (Córdoba) males from 18 families and females from 17, 357 from Buenaventura (Valle del Cauca) males from 24 families and females from 16 and 232 from Tibú (North of Santander) males from 32 families and females from 15. Based on the presence or absence of costal dark and pale spots, eight distinct wing spot patterns were observed, seven in males and seven in females; only one pattern was found either on males (pattern VIII) or females (pattern V), but not in both. In male progeny from all three localities, the most frequent patterns were I (85.38\%), III $(8.81 \%)$ and VI (3.62\%), and the least frequent patterns were II $(1.42 \%)$, IV $(0.47 \%)$ and VII and VIII $(0.16 \%)$. For females, the most frequent patterns were I $(66.25 \%)$, III (15.38\%), II (9.16\%) and VI (5.45\%), and the least frequent patterns were IV $(1.98 \%), \mathrm{V}(0.74 \%)$ and VII (0.99\%) (Fig. 3).

Comparison of male and female costal wing patterns of the three populations showed that specimens from Buenaventura municipality had the highest morphological variability $(87.5 \%)$, whereas for individuals from Tibú it was $75 \%$, and in Tierralta, only $50 \%$. For those individuals from the Tierralta population, we observed wing patterns I to IV. Our results were concordant with the results of other studies carried out on An. nuneztovari from other Latin American countries. For example,
Hribar (1995) observed six wing patterns and Delgado and Rubio-Palis (1992) found eight patterns for species of the subgenus Nyssorhynchus. Delgado and RubioPalis' Type I was observed in all examined species and is similar to pattern I found in An. nuneztovari populations reported here. Pattern III of An. nuneztovari was not observed by any of the previous studies. Gonzalez (2001) found 14 wing patterns when analyzing progenies of Anopheles darlingi from Colombia. Patterns I and II were coincident with those of the present study, whereas pattern $\mathrm{X}$ is identical to pattern III of the present study.

The frequency of wing patterns in each locality is in Table I. In both males and females, pattern I was the most common, found in $77.96 \%$ of individuals; approximately $66 \%$ of the females and $85 \%$ of males. This pattern corresponds to that described by Faran (1980) and Wilkerson and Peyton (1990), and Type A of Hribar (1995), i.e. ASP is present (Table I) and represents a significant difference between the sexes. In pattern II, ASP is absent. Absence of ASP was observed in $9.16 \%$ of all females and but is present in only $1.42 \%$ of males; however, it was more frequent in those progenies from Tierralta $(18.37 \%)$ and nearly absent in individuals from the other two localities. In Buenaventura only $1.0 \%$ of the specimens showed pattern II. Pattern III has a large wing pale spot proximal to DSD, which is a result of the fusion of SP, PRSD and ASP. This pattern was the second most frequent in $15.38 \%$ of females and $8.81 \%$ of males. Pattern IV, represented by the fusion of HD and PSP, was found in approximately $2.0 \%$ of all females $(0.5 \%$ of the males); however, it was almost exclusively in the progenies from Buenaventura ( $8.1 \%$ of the samples). Pattern VI, absence of SP, was observed in low frequency $(5.45 \%$ of all examined females); however, it was found in several progenies from all three localities. The following wing patterns were found in very low frequencies but they should be considered when analyzing wing pattern variation because they may complicate species identification: $\mathrm{V}(0.74 \%)$ and VII $(1 \%)$ were exclusive to females from Buenaventura (3.0\% and $4.0 \%$ respectively); and, VIII was observed only in adult males from Tibú (0.3\%) (Table I).

Description of diagnostic characters of adult female An. nuneztovari - Identification of female mosquitoes is required for ecological and vector competence studies. In an attempt to improve methods for their identification, we analyzed the diagnostic characters (wing and hindtarsomere II) for this stage to include costal dark and pale spots patterns I to VII and the ratios of HP/PHD, SCP/ DSD and length of basal dark spot (DS-Ta-III ${ }_{2}$ / length of hindtarsomere II ( $\mathrm{Ta}^{-\mathrm{III}_{2}}$ ) (Table II).

Results of the comparative analyses employing individuals of distinct progenies showed that the pale and dark spot wing patterns varied in at least $5 \%$ of the samples such that those specimens could be misidentified as another species of Nyssorhynchus. This was because our observations of the ranges of variation of wing pale and dark spots were higher than that shown by Faran (1980). Similarly, Delgado and Rubio-Palis (1993) observed the same range variation in wing dark and pale spots pat- 


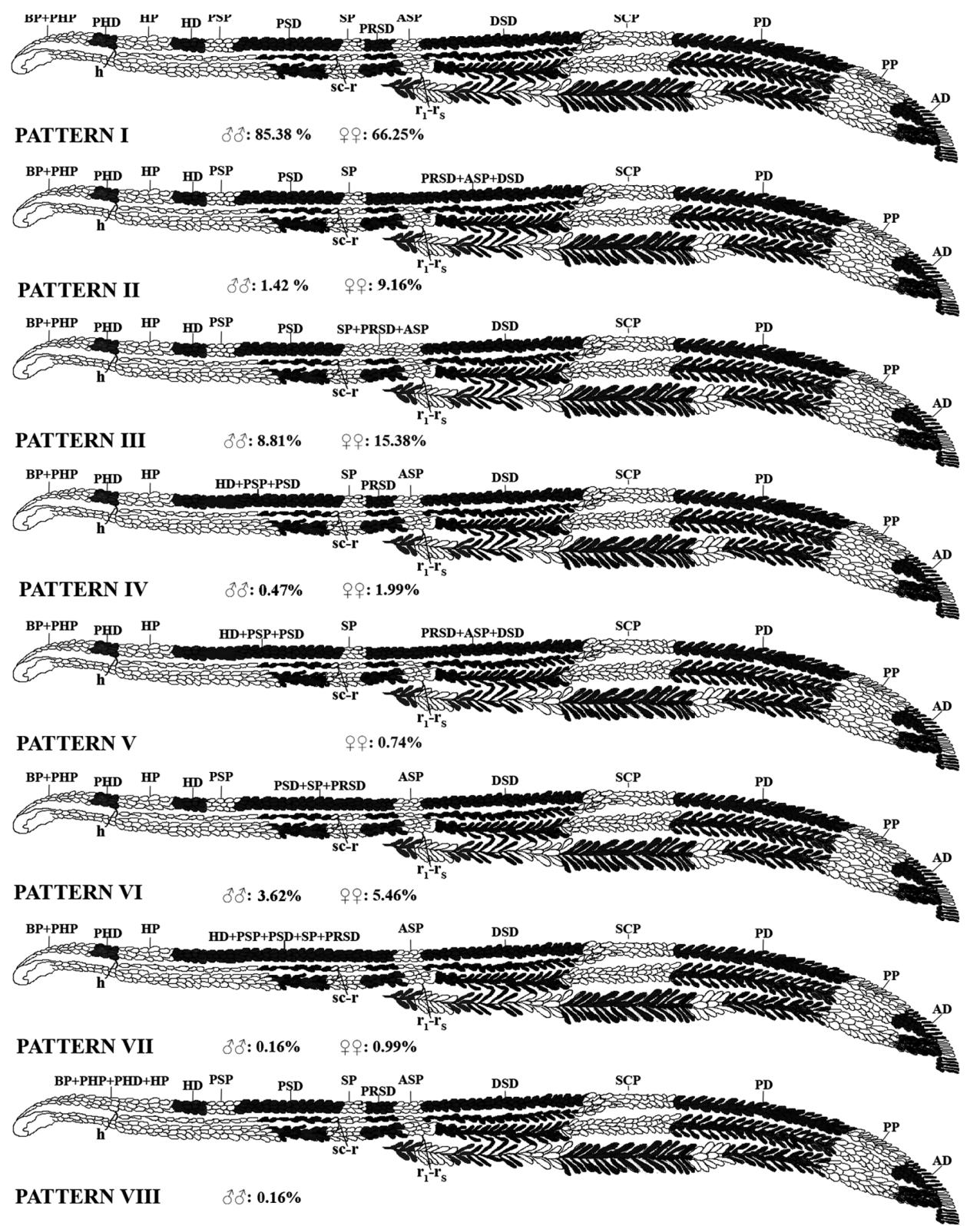

Fig. 3: dark and pale spots costal wing pattern (I-VIII) and percentage of males and females that possess each pattern, in Anopheles nuneztovari from three localities in Colombia. Pattern V is present only in females, whereas VIII only in males.

terns. Comparing the variation of the other characters used for species identification with the most frequent costal wing pattern, I and III, ( $\mathrm{n}=329$ individuals) showed that $4.56 \%$ of the samples had a ratio DS-Ta-III $/ \mathrm{Ta}^{\mathrm{TII}} \mathrm{I}_{2}$ lower than 0.25 (0.21 to 0.24$)$. Among them, only $3.34 \%$ showed an HP/PHD ratio lower than 1.50. In this case variation was 1.33 and 1.60 for pattern III and 0.86 to 1.67 for pattern I. Consequently, when using adult identification keys by Faran (1980) and Faran and Linthicum (1981), with respect to these two characters, $1.52 \%$ of the individuals can be misidentified as Anopheles oswaldoi. When considering those specimens that show costal dark and pale spots patterns II and V, the first difficulty is the impossibility of estimating the ratio of the length of SCP/ DSD because it is impossible to differentiate the ASP. In both patterns II and V the sector dark spot is continuous, not being divided in two distinct spots; consequently it is impossible to differentiate the DSD spot, and thus the ratio is $\mathrm{SCP} / \mathrm{SD}$, which makes this ratio decrease in comparison to the other ratios. In those specimens with wing pattern II, only $0.50 \%$ of females possess DS-Ta-III $/ 2$ TaIII, less than 0.25; however, in those females where the ratio HP/PHD is in between 1.14 and 2.00 and the ratio $\mathrm{SCP} / \mathrm{SD}$ is lower than 0.50 , it is possible to distinguish An. nuneztovari from Anopheles rangeli, but at least one of the two species can be misidentified as An. oswaldoi. No individual possessing wing pattern IV, V and VIII was found to have DS-Ta-III $/$ Ta-III ${ }_{2}$ lower than 0.25 .

More difficulties were observed in identifying those specimens in which the ratio DS-Ta-III/ $/ \mathrm{Ta}-\mathrm{III}_{2}$ was higher than 0.25 . In those samples with wing spot pattern I and III, the ratio DS-Ta-III/Ta-III, varied from 
TABLE I

Frequency of patterns of pale and dark wing spots in male and female adults of Anopheles nuneztovari in three departments in Colombia

\begin{tabular}{|c|c|c|c|c|c|c|c|}
\hline \multirow[b]{2}{*}{ Pattern } & \multirow[b]{2}{*}{ Department } & \multicolumn{2}{|c|}{ Females } & \multicolumn{2}{|c|}{ Males } & \multicolumn{2}{|c|}{ Total } \\
\hline & & $\mathrm{n}$ & $\%$ & $\mathrm{n}$ & $\%$ & $\mathrm{n}$ & $\%$ \\
\hline \multirow[t]{4}{*}{ I } & Norte De Santander & 86 & 79.63 & 217 & 85.43 & 303 & 83.70 \\
\hline & Valle Del Cauca & 72 & 72.73 & 230 & 89.15 & 302 & 84.59 \\
\hline & Córdoba & 109 & 55.61 & 96 & 77.42 & 205 & 64.06 \\
\hline & Total & 267 & 66.25 & 543 & 85.38 & 810 & 77.96 \\
\hline \multirow[t]{3}{*}{ II } & Valle Del Cauca & 1 & 1.01 & 0 & 0.00 & 1 & 0.28 \\
\hline & Córdoba & 36 & 18.37 & 9 & 7.26 & 45 & 14.06 \\
\hline & Total & 37 & 9.16 & 9 & 1.42 & 46 & 4.43 \\
\hline \multirow[t]{4}{*}{ III } & Norte De Santander & 12 & 11.11 & 20 & 7.87 & 32 & 8.84 \\
\hline & Valle Del Cauca & 4 & 4.04 & 18 & 6.98 & 22 & 6.16 \\
\hline & Córdoba & 46 & 23.47 & 18 & 14.52 & 64 & 20.00 \\
\hline & Total & 62 & 15.38 & 56 & 8.81 & 118 & 11.36 \\
\hline \multirow[t]{3}{*}{ IV } & Norte De Santander & 0 & 0.0 & 1 & 0.39 & 1 & 0.55 \\
\hline & Valle Del Cauca & 8 & 8.08 & 2 & 0.78 & 10 & 2.80 \\
\hline & Total & 8 & 1.98 & 3 & 0.47 & 11 & 1.15 \\
\hline \multirow[t]{2}{*}{ V } & Valle Del Cauca & 3 & 3.03 & 0 & 0.00 & 3 & 0.84 \\
\hline & Total & 3 & 0.74 & 0 & 0.00 & 3 & 0.29 \\
\hline \multirow[t]{4}{*}{ VI } & Norte De Santander & 10 & 9.26 & 14 & 5.51 & 24 & 6.35 \\
\hline & Valle Del Cauca & 7 & 7.07 & 8 & 3.10 & 15 & 4.20 \\
\hline & Córdoba & 5 & 2.55 & 1 & 0.81 & 6 & 1.88 \\
\hline & Total & 22 & 5.45 & 23 & 3.62 & 45 & 4.23 \\
\hline \multirow[t]{3}{*}{ VII } & Norte De Santander & 0 & 0.00 & 1 & 0.39 & 1 & 0.28 \\
\hline & Valle Del Cauca & 4 & 4.04 & 0 & 0.00 & 4 & 1.12 \\
\hline & Total & 4 & 0.99 & 1 & 0.16 & 5 & 0.48 \\
\hline \multirow[t]{2}{*}{ VIII } & Norte De Santander & 0 & 0.00 & 1 & 0.39 & 1 & 0.28 \\
\hline & Total & 0 & 0.00 & 1 & 0.16 & 1 & 0.10 \\
\hline Total & & 403 & 100 & 636 & 100 & 1039 & 100 \\
\hline
\end{tabular}

0.25 to 0.42 and the HP/PHD ratio varied from 0.60 to 3.80, whereas the ratio $\mathrm{SCP} / \mathrm{DSD}$ varied between 0.21 and 0.70 (Table III). Consequently, in dealing with the ratio variation of these three characters, it is important to be able to accurately separate species of the Oswaldoi Group; however, keeping in mind that these variations may cause some difficulty. One of the first problems to be observed was that $34.45 \%$ of the samples showed SCP/ DSD ratio higher than 0.50 , a cutoff point in separating the species of this group. Also, among the $34.45 \%$ individuals, in $3.65 \%$ the HP/PHD ratio is higher than 1.8 , another cutoff point among the extremes of phenotype variation, which in combination with the previous characteristics, allowed us to approximate the identification of those specimens as An. rangeli. Consequently, when identifying individuals that possess any of these character variations, the absence of upper mesepimeral scales will be important for separating a high percentage of individuals of An. nuneztovari from those of An. rangeli in which characters can overlap. The results of all character measurements and comparisons made in this study using specimens derived from the isogenic progenies of
An. nuneztovari from Colombia show that, it is a difficult task to distinguish An. nuneztovari from the remaining species of the Oswaldoi Group, (except for Anopheles triannulatus, An. rangeli and An. oswaldoi), using either Faran's (1980) or Faran and Linthicum's (1981) adult keys, because these characters overlap in an important percentage of individuals of several species (Table III).

Because a percentage of the individuals possessing wing patterns I and III showed a DS-Ta- $\mathrm{III}_{2} / \mathrm{Ta}-\mathrm{III}_{2}$ ratio equal to or higher than 0.40 , a low percentage of the samples (2.43\%) can be misidentified as either Anopheles aquasalis or Anopheles benarrochi. On the other hand, those individuals with the same wing patterns I and III, in which ratio HP/PHD is higher that 2.0, can be misidentified as Anopheles trinkae, Anopheles strodei or Anopheles evansae. Similarly, Delgado and Rubio-Palis (1993) reported the same increase in the range of variation of the HP/PHD ratio in An. nuneztovari that, in addition to the character variation observed in other species of the Oswaldoi Group in Venezuela, was used to put forth a new sequence of range variations for those characters which then made possible a new identification key for species of the subgenus Nyssorhynchus in Venezuela. 


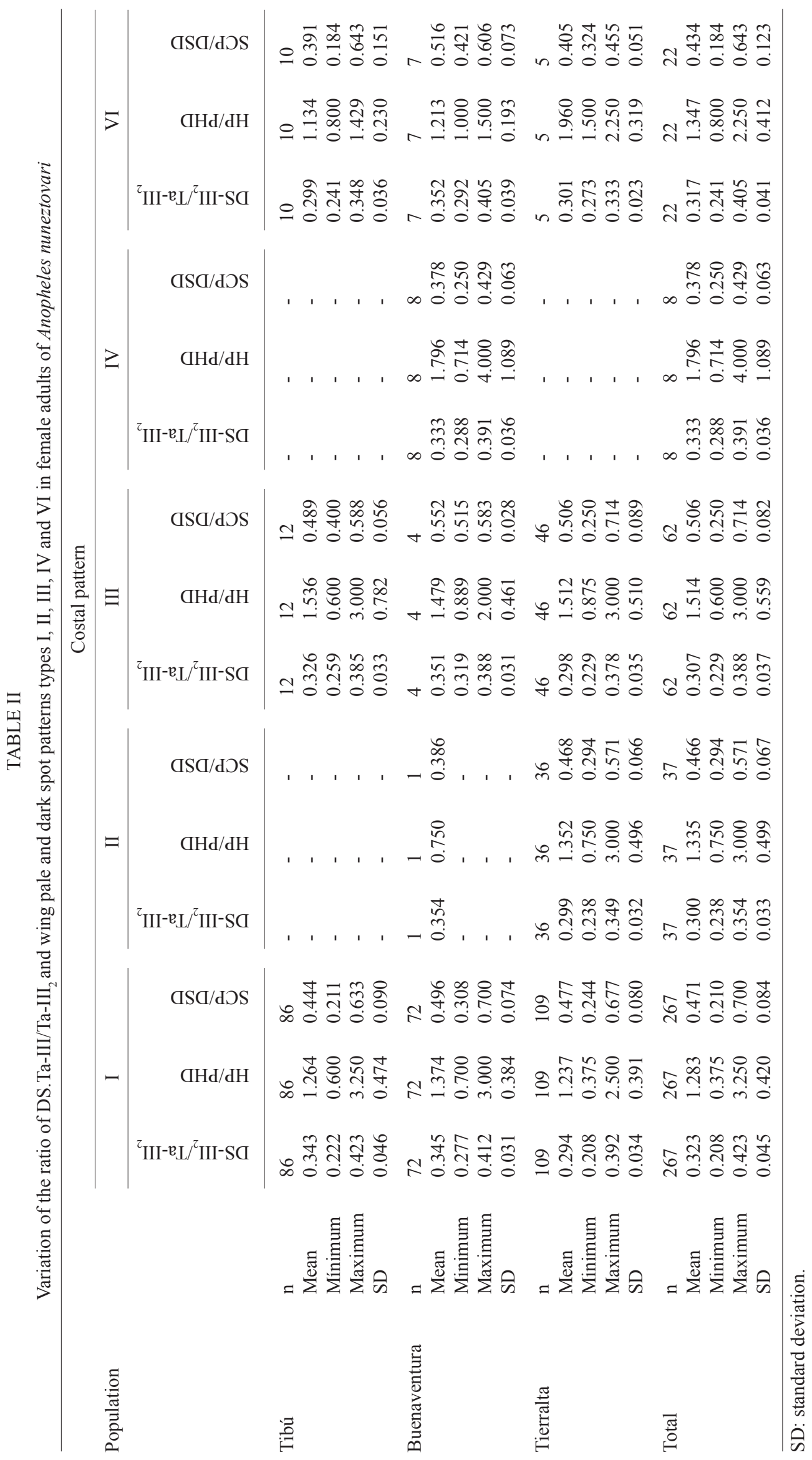


As a result, based on what was observed in three populations of An. nuneztovari from Colombia, it will be necessary to make additional adjustments and reevaluate character range variation in other species of the subgenus Nyssorhynchus. Character ranges were re-evaluated for the identification key proposed by González and Carrejo (2007). It is therefore evident to us that it will be necessary to use additional morphological characters, some of them already reported in Faran (1980) Faran and Linthicum (1981) and Rubio-Palis (2000), to separate those species that are difficult to identify based only on adult female characters. For example, according to Rubio-Palis (2000), adult females of An. benarrochi and An. aquasalis can be differentiated by the percentage of dark scales on wing vein M. Consequently, to distinguish specimens of those two species it will be necessary to examine this character. Additionally, An. nuneztovari and An. strodei can be differentiated when using Faran's (1980) characters on the basis of the wing scale color in the anterior veins, which are light cream to white in $A n$. strodei, whereas it is cream to yellowish in An. nuneztovari. Complementary morphological studies will be necessary to establish characters to separate specimens of An. strodei from An. trinkae because polymorphism and overlap may confuse species identification, especially with those that share some of the same character variation found for An. nuneztovari. This is the case with An. evansae, a species that was found in Meta department, situated in the Eastern slope of the Andes. A. evansae was reported in Colombia by Faran (1980), however, there is not a recent report of the presence of this species in the country. It is possible that a morphological variant of An. nuneztovari might be misidentified as An. evansae. For the latter species, there are scanning electron microscope (SEM) photos of the eggs reported from Colombia. However, considering the polymorphism observed in the present study, we can assume that the SEM report might refer to an An. nuneztovari variant.

\section{TABLE III}

Variation of the ratio of wing spots the ratio of the length of the subcostal pale spot/length of the distal sector dark spot (SCP/DSD) lower than 0.53 and higher than 0.53 and their relation with respective ranges of the ratio of the length of the humeral pale spot/length of the pre-humeral dark spot (HP/PHD) and the ratio of the length of the basal dark area of hind tarsomere II/length of hind tarsomere II (DS-Ta-III $/ 2$ Ta-III ${ }_{2}$ ), observed in individuals of progenies of Aopheles nuneztovari of three departments in Colombia

\begin{tabular}{|c|c|c|c|c|c|c|}
\hline Pattern & DS-Ta-III $2 /$ Ta-III ${ }_{2}$ & HP/PHD & $\mathrm{n}$ & DS-Ta-III $2 /$ Ta-III ${ }_{2}$ & HP/PHD & $\mathrm{SCP} / \mathrm{DSD}$ \\
\hline \multirow[t]{10}{*}{ I } & $0.21-0.24$ & $0.86-1.67$ & 7 & $0.21-0.24$ & $1.00-1.67$ & $0.30-0.53$ \\
\hline & & & 4 & $0.23-0.24$ & $0.87-1.17$ & $0.53-0.65$ \\
\hline & $0.25-0.40$ & $0.38-0.67$ & 7 & $0.26-0.34$ & $0.50-0.67$ & $0.34-0.53$ \\
\hline & & & 2 & $0.30-0.33$ & $0.38-0.67$ & $0.57-0.59$ \\
\hline & & $0.71-1.80$ & 163 & $0.25-0.39$ & $0.71-1.80$ & $0.21-0.53$ \\
\hline & & & 46 & $0.26-0.39$ & $0.75-1.80$ & $0.53-0.68$ \\
\hline & & $1.83-3.25$ & 18 & $0.26-0.40$ & $1.83-3.25$ & $0.30-0.53$ \\
\hline & & & 6 & $0.31-0.38$ & $1.83-3.00$ & $0.53-0.70$ \\
\hline & $0.40-0.42$ & $0.80-1.50$ & 9 & $0.40-0.42$ & $1.00-1.50$ & $0.37-0.53$ \\
\hline & & & 5 & $0.40-0.42$ & $0.80-1.00$ & $0.53-0.63$ \\
\hline \multirow[t]{10}{*}{ III } & $0.229-0.24$ & $1.33-1.60$ & 1 & 0.23 & 1.50 & 0.47 \\
\hline & & & 2 & $0.23-0.24$ & $1.33-1.60$ & $0.55-0.71$ \\
\hline & & 2.33 & 1 & 0.24 & 2.33 & 0.67 \\
\hline & $0.25-0.39$ & 0.60 & 1 & 0.31 & 0.60 & 0.50 \\
\hline & & $0.87-1.80$ & 20 & $0.25-0.38$ & $1.00-1.80$ & $0.39-0.52$ \\
\hline & & & 20 & $0.26-0.39$ & $0.88-1.80$ & $0.53-0.64$ \\
\hline & & & 7 & $0.26-0.36$ & $1.00-1.67$ & $0.44-0.50$ \\
\hline & $0.25-0.39$ & $2.00-3.00$ & 2 & $0.36-0.39$ & $2.00-3.00$ & $0.44-0.53$ \\
\hline & & & 6 & $0.25-0.33$ & $2.00-3.00$ & $0.25-0.44$ \\
\hline & & & 4 & $0.30-0.32$ & $2.00-3.00$ & $0.53-0.58$ \\
\hline \multirow[t]{2}{*}{ IV } & $0.29-0.39$ & $0.71-1.33$ & 5 & $0.30-0.39$ & $0.71-1.33$ & $0.25-0.43$ \\
\hline & & $2.00-4.00$ & 3 & $0.29-0.32$ & $2.00-4.00$ & $0.32-0.42$ \\
\hline \multirow[t]{6}{*}{ VI } & 0.24 & 0.80 & 1 & 0.24 & 0.80 & 0.25 \\
\hline & $0.25-0.38$ & $1.00-1.80$ & 3 & $0.29-0.35$ & 1.00 & $0.18-0.25$ \\
\hline & & & 9 & $0.25-0.38$ & $1.00-1.80$ & $0.32-0.53$ \\
\hline & & & 5 & $0.29-0.37$ & $1.00-1.50$ & $0.53-0.64$ \\
\hline & & $2.00-2.25$ & 3 & $0.27-0.31$ & $2.00-2.25$ & $0.40-0.45$ \\
\hline & 0.40 & 1.00 & 1 & 0.40 & 1.00 & 0.48 \\
\hline
\end{tabular}


Identification key for species of the Oswaldo Group of Colombia that can be misidentified as An. nuneztovari (An. triannulatus is excluded):

1 Hindtarsomere 2 ( $\mathrm{Ta}-\mathrm{III}_{2}$ ) with a basal dark area smaller that 0.25 of the hindtarsomere length ............. 2

1 ' Hindtarsomere $2\left(\mathrm{Ta}-\mathrm{III}_{2}\right)$ with a basal dark area longer than 0.25 of the hindtarsomere length

2(1) Foretarsomere 4 (Ta-I4) varying from dark in about 0.3 basal to entirely dark-scaled; ta- $\mathrm{II}_{4}$ entirely dark; ratio of HP/PHD more than 1.0 (1.0-3.5); SCP/ DSD 0.11-0.44 (Figure 8.73) oswaldoi

2' Foretarsomere 4 (Ta-I4) distinct; $\mathrm{Ta}_{4} \mathrm{II}_{4}$, ratio of HP/PHD; SCP/DSD variable, never as above ........... 3

3 (2') SCP/DSD normally equal or greater than 0.55 (0.53-1.40); HP/PHD generally greater than 2.0; generally with upper mesepimeral pale scales............ rangeli

3' SCP/DSD normally lower then 0.55 , if greater than 0.55 , then HP/PHD equal or smaller than 2.0 ; generally upper mesepimeral pale scales absent or without costal PRSD wing vein spot (SP+PRSD+ASP) ... nuneztovari, strodei

$4\left(1^{\prime}\right) \mathrm{SCP} / \mathrm{DSD}$ generally equal or greater than 0.55 (0.53-1.40); HP/PHD generally greater than 2.0; generally with upper mesepimeral pale scales .......... rangeli

4' SCP/DSD generally smaller than 0.55 , if greater than 0.55 , then HP/PHD generally equal or smaller than 2.0; generally without upper mesepimeral pale scales .... 5

5(4') Hindtarsomere 2 ( Ta-III $_{2}$ ) with basal dark area greater or equal to 0.44 total lenght of the tarsomere 2 strodei, benarrochi, aquasalis

5' Hindtarsomere 2 ( $\mathrm{Ta} \mathrm{III}_{2}$ ) with basal dark area smaller than $0.44(0.25-0.43)$ total lenght of the tarsomere 2 ...... 6

$6\left(5^{\prime}\right)$ Humeral pale spot (HP) smaller than 2.0 the length of the dark prehumeral spot (PHD) ... nuneztovari, trinkae, strodei, evansae*

6' Humeral pale spot (HP) equal or greater than 2.0 the length of the dark prehumeral spot (PHD) .... nuneztovari, strodei, evansae*

* Current evidences suggest that this species does not occur in Colombia.

\section{ACKNOWLEDGMENTS}

To Mr. Henry R. Rupp for kindly reviewing the English and for translating the introduction from Spanish into English. To Nancy Carrejo (Biology Department of Universidad del Valle), Catalina Gutierrez and Raúl Ernesto Gonzalez. To LJ Hribar for sent us his own papers. This research was performed under a Memorandum of Understanding between the Walter Reed Army Institute of Research and the Smithsonian Institution, with institutional support provided by both organizations. The material to be published reflects the views of the authors and should not be construed to represent those of the US Dept. of the Army or the Dept. of Defense.

\section{REFERENCES}

Bergo ES, Souto RN, Galardo AK, Nagaki SS, Calado DC, Sallum MA 2007. Systematic notes on Anopheles Meigen (Diptera: $\mathrm{Cu}-$ licidae) species in the state of Amapá, Brazil. Mem Inst Oswaldo Cruz 102: 373-376.
Conn JE, Mitchell SE, Cockburn AF 1998. Mitochondrial DNA analysis of the neotropical malaria vector Anopheles nuneztovari. Genome 41: 313-327.

Conn JE, Rangel Y, Seawright JA 1993. A new cytotype of Anopheles nuneztovari from western Venezuela and Colombia. J Am Mosq Control Assoc 9: 294-301.

Delgado N, Rubio-Palis Y 1992. Morphometric characterization of the malaria vector Anopheles nuneztovari (Diptera: Culicidae) from western Venezuela. Mosq Syst 24: 231-241.

Delgado N, Rubio-Palis Y 1993. Identification of Anopheles (Nyssorhynchus) (Diptera: Culicidae) occurring in western Venezuela. Mosq Syst 25: 222-229.

Elliott R 1972. The influence of vector behavior on malaria transmission. Am J Trop Med Hyg 21: 755-763.

Faran ME 1980. Mosquito studies (Diptera, Culicidae) XXXIV. A revision of the Albimanus Section of the subgenus Nyssorhynchus of Anopheles. Contrib Amer Entomol Inst 15: 1-215.

Faran M, Linthicum KJ 1981. A handbook of the Amazonían species of Anopheles (Nyssorhynchus) (Diptera: Culicidae). Mosq Syst 13: 1-81.

Gabaldon A 1940. Estudios sobre Anophelinos. Serie I. 1. Descripción de Anopheles (Nyssorhynchus) nuneztovari n. sp. y consideraciones sobre una sub-división del grupo Nyssorhynchus (Diptera: Culicidae). Venez Div Malario Publ 5: 3-7.

González R 2001. Análisis morfométrico y molecular de Anopheles (Nyssorhynchus) darlingi Root, 1926. (Diptera: Culicidae) de Colombia. PhD Thesis, Universidad del Valle, Cali, 215 pp.

González R, Carrejo N 2007. Introducción al estudio Taxonómico de Anopheles de Colombia Claves y notas de distribución, 1st ed., Universidad del Valle, Cali, 237 pp.

Hribar LJ 1994. Geographic variation of male genitalia of Anopheles nuneztovari (Diptera: Culicidae). Mosq Syst 26: 132-144.

Hribar LJ 1995. Costal wing spot variations within and among progeny of single female Anopheles nuneztovari (Diptera: Culicidae). Mosq Syst 27: 1-10.

Instituto Geográfico "Agustín Codazzi”. Subdirección de Investigaciones y Divulgación Geográfica 1980. Diccionario geográfico de Colombia. Tomos I, II, 2nd ed., Bogotá, 1813 pp.

Kitzmiller JB, Kreutzer RD, Tallaferro E 1973. Chromosomal differences in populations of Anopheles nuneztovari. WHO Bull 48: 435-455.

Lane J 1953. Neotropical Culicidae, Vol. I, Univ. São Paulo, 548 pp.

Lounibos LP, Conn JE 2000. Malaria vector heterogeneity in South America. Am Entomol 46: 238-249.

Posso CE, González R, Cárdenas H, Gallego G, Duque MC, Suárez MF 2003. Random amplified polymorphic DNA analysis of Anopheles nuneztovari (Diptera: Culicidae) from Western and Northeastern Colombia. Mem Inst Oswaldo Cruz 98: 469-476.

Rosa-Freitas M, Lourenço-de-Oliveira R, Carvalho-Pinto J, FloresMendosa C, Silva-do-Nacimento T 1998. Anopheline species complexes in Brazil. Current knowledge of those related to malaria transmission. Mem Inst Oswaldo Cruz 93: 651-655.

Rubio-Palis Y 2000. Anopheles (Nyssorhynchus) de Venezuela: taxonomía, bionomía, ecología e importancia médica. Esc Malariol Y San Amb "Dr. Arnoldo Gabaldon", Maracay 118 pp.

Scarpassa VM, Tadei WP, Suárez MF 1999. Population structure and genetic divergence in of Anopheles nuneztovari (Diptera: Culicidae) from Brazil and Colombia. Am J Trop Med Hyg 60: 1010-1018.

Sutil OE 1976. Redescripción de la especie Anopheles (Nyssorhynchus) nuneztovari Gabaldon, 1940, y su distribución geográfica en Venezuela. Bol Dir Malariol Saneamiento Ambiental 16: 3 3-45.

Wilkerson RC, Peyton EL 1990. Standardized nomenclature for the costal wing spots of the genus Anopheles and other spotted-wing mosquitoes (Diptera: Culicidae). J Med Entomol 27: 207-224. 